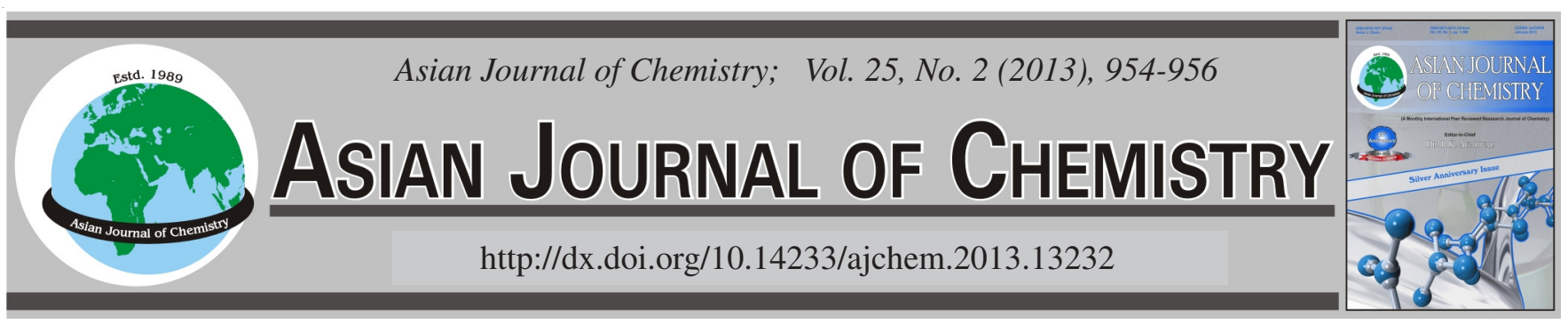

\title{
Ethylbenzotriazolium Bromide Ionic Liquid: A New Water Soluble Inhibitor for Corrosion of Mild Steel in Acid Media
}

\author{
Hongmei Wang ${ }^{1,2}$, Sulin Liu ${ }^{1, *}$, Kelong Huang ${ }^{1}$, Younian Liu ${ }^{1}$ and Zhaonan Li $^{2}$
}

${ }^{1}$ College of Chemistry and Chemical Engineering, Central South University, Changsha 410083, Hunan Province, P.R. China

${ }^{2}$ Hunan Provincial Key Laboratory of Materials Protection for Electric Power and Transportation, School of Chemistry and Biological Engineering, Changsha University of Science and Technology, Changsha 410004, Hunan Province, P.R. China

*Corresponding author: Tel./Fax: +86 731 888798501; E-mail: wanghm123@126.com; sqliu2003@126.com

\begin{abstract}
The inhibiting effect of 1-ethyl-3-ethylbenzotriazolium bromide ionic liquid, $\left[\mathrm{C}_{2} \mathrm{Et}\right] \mathrm{Br}$, on the corrosion behaviour of mild steel in $5 \mathrm{wt}$. $\% \mathrm{HCl}$ was investigated by using various techniques such as weight loss, potentiodynamic polarization and electrochemical impedance spectroscopy. All studies showed that the increase in inhibition efficiency and decrease in the corrosion rate by increasing the inhibitor concentration. Polarization measurements indicated that the $\left[\mathrm{C}_{2} \mathrm{Et}\right] \mathrm{Br}$ acted essentially as a mixed-type inhibitor. The electrochemical impedance study showed that corrosion inhibition took place by adsorption.

Key Words: Benzotriazolium ionic liquid, Corrosion, Steel, Polarization, EIS, Acid solution.
\end{abstract}

\section{INTRODUCTION}

Acid solutions are commonly used in the chemical industry to remove the scales from the metallic surfaces. The addition of inhibitors secures the metal against an acid attack effectively. The applicability of organic compounds as corrosion inhibitors for metals in acidic media has been recognized for a long time. The existing data show that most of the organic inhibitors act by adsorption on the metal surface ${ }^{1-6}$. The adsorption of inhibitors occurs through heteroatoms such as nitrogen, oxygen, phosphorus and sulphur as well as a triple bond or an aromatic ring.

It has been observed that adsorption depends mainly on certain physicochemical properties of the inhibitor group, such as electron density at the donor atom, $\pi$-orbital character and the electronic structure of the molecule. Imidazolium compounds and benzotriazole derivatives are reported to show corrosion resistant behaviour on copper, mild steel and aluminum. It was found that the action of such inhibitors depends on the specific interaction between the functional groups and the metal surface, due to the presence of the $-\mathrm{C}=\mathrm{N}$-group, -N=N-group and electronegative nitrogen in the molecule.

Ionic liquids are molten salts, which are made up only from two asymmetrical ions of opposite charges and have a melting point of $<100{ }^{\circ} \mathrm{C}$ or are ideally, even liquid at ambient temperature. They have found their application in different areas as organic synthesis, catalysts, energy storage devices, etc. ${ }^{6}$. How- ever, ionic liquids were used as metallic corrosion inhibitors. Up to date, there was little information on imidazolium ionic liquids used as corrosion inhibitors in acid medium ${ }^{1-3}$.

Our previous work ${ }^{7}$ showed that the benzotriazolium ionic liquids could be used as a corrosion inhibitor in acid medium. The aim of this work is to investigate the inhibiting influence of 1-ethyl-3-ethylbenzotriazolium bromide, $\left[\mathrm{C}_{2} \mathrm{Et}\right] \mathrm{Br}$, on mild steel (MS) corrosion in 5 wt. \% hydrochloric acid solution. This has been studied by weight loss, potentiodynamic polarization and electrochemical impedance spectroscopy (EIS) techniques. To our best knowledge, the benzotriazole ionic liquid, $\left[\mathrm{C}_{2} \mathrm{Et}\right] \mathrm{Br}$ has been firstly used as corrosion inhibitors in acid medium.

\section{EXPERIMENTAL}

The synthetic route of $\left[\mathrm{C}_{2} \mathrm{Et}\right] \mathrm{Br}$ is depicted in Fig. 1. First 1-ethylbenzotriazole was synthesized by a reaction of benzotriazole and ethylbromide in aqueous sodium hydroxide solution using tetrabutylammonium bromide as phase transfer reagent and then 1-ethylbenzotriazole was further quaternized with ethylbromide. The specific steps were similar to those described previously ${ }^{8}$. The chemical structure of product was checked by IR (Aratar-360, American) and ${ }^{1} \mathrm{H}$ NMR [Avance(III), Bruker]. The corresponding spectral characteristics were described as following. IR (KBr, $v_{\max }, \mathrm{cm}^{-1}$ pellet): 3484, 3038, 2969, 2873, 1607, 1453, 1379, 1255, 1146, 772, 754. ${ }^{1} \mathrm{H}$ NMR (400 MHz, $\left.\mathrm{CDCl}_{3}\right) 1.71(\mathrm{t}, 6 \mathrm{H}), 5.16(\mathrm{q}, 4 \mathrm{H}), 7.84(\mathrm{~m}, 2 \mathrm{H}), 8.47(\mathrm{~d}, 2 \mathrm{H})$. 


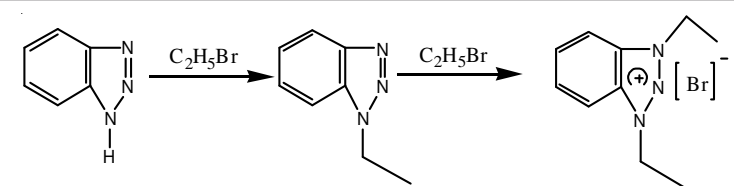

Fig. 1. Structure and synthesis of 1-ethyl-3-ethylbenzotriazolium ionic liquid

Prior to all measurements, the mild steel samples are polished successively with fine grade emery papers from 400 to 1200 grade. The specimens are rinsed thoroughly with double-distilled water, degreased in absolute ethanol and dried by compressed air at room temperature. The aggressive solution $5 \mathrm{wt} . \% \mathrm{HCl}$ is prepared by dilution of AR grade $37 \mathrm{wt} . \%$ $\mathrm{HCl}$ with double distilled water. The concentration range of inhibitor employed was $2-40 \mathrm{mmol} / \mathrm{L}$ in acid solutions.

Weight loss experiments were performed on mild steel samples with a rectangular form in $5 \mathrm{wt} . \% \mathrm{HCl}$ with and without addition of different concentrations of inhibitor. Every sample was weighted by an electronic balance and then placed in the acid solution $(100 \mathrm{~mL})$. The duration of the immersion was $5 \mathrm{~h}$ at $323 \mathrm{~K}$, the solution temperature was by thermostatically controlled. After immersion, the surface of the specimen was cleaned by anhydrous alcohol rinsing and the sample was reweighted in order to calculate the corrosion rate.

Electrochemical experiments were carried out using an electrochemical work station(CHI660D, ShangHai). A conventional three-electrode arrangement at $323 \mathrm{~K}$ under atmospheric condition was used for electrochemical studies. Working electrode was prepared from a MS sheet, mounted in polyester so that the area exposed to corrosive solution was $1 \mathrm{~cm}^{2}$. A saturated calomel electrode (SCE) and a $1 \mathrm{~cm} \times 1 \mathrm{~cm}$ platinum electrode were used as the reference and counter electrodes, respectively. For potentiodynamic polarization measurements the potential sweep rate was $10 \mathrm{mVs}^{-1}$ in the potential range from $150 \mathrm{mV}$ below the open circuit potential to $150 \mathrm{mV}$ above the open circuit potential. The impedance measurements were carried out in the frequency range of $100 \mathrm{kHz}$ to $1 \mathrm{~Hz}$ with a signal amplitude perturbation of $5 \mathrm{mV}$ at the open circuit potential (OCP). All potentials were recorded with respect to the saturated calomel electrode.

\section{RESULTS AND DISCUSSION}

Weight loss measurements: The weight loss results regarding the corrosion parameters for mild steel in $5 \mathrm{wt}$. \% $\mathrm{HCl}$ solution in the absence and presence of different concentrations of inhibitor are summarized in Table-1.

TABLE-1

WEIGHT LOSS DATA OF MILD STEEL IN 5 wt. \% $\mathrm{HCl}$ FOR VARIOUS CONCENTRATION OF $\left[\mathrm{C}_{2} \mathrm{Et}\right] \mathrm{Br}$

\begin{tabular}{ccc}
\hline Inhibitor conc. $(\mathrm{mmol} / \mathrm{L})$ & $\mathrm{CR}_{\text {corr }}\left(\mathrm{gm}^{-2} \mathrm{~h}^{-1}\right)$ & $\mathrm{IE}(\%)$ \\
\hline Blank & 13.770 & - \\
2 & 7.340 & 46.7 \\
4 & 5.811 & 57.8 \\
10 & 4.943 & 64.1 \\
20 & 3.924 & 71.5 \\
40 & 2.700 & 80.4 \\
\hline
\end{tabular}

The inhibition efficiency was calculated by using the following eqn. $(1)^{3}$, where $\mathrm{CR}_{0}$ and $\mathrm{CR}_{\text {inh }}$ are the corrosion rates of mild steel with and without the inhibitor, respectively. It can be observed that corrosion rate values of mild steel decrease when the inhibitor concentration increases. The inhibition (IE) increases with increasing the concentrations, reaching a maximum value $(80.4 \%)$ of $40 \mathrm{mmol} / \mathrm{L}$ of $\left[\mathrm{C}_{2} \mathrm{Et}\right] \mathrm{Br}$. Gravimetric measurements confirm the protection property of $\left[\mathrm{C}_{2} \mathrm{Et}\right] \mathrm{Br}$ in $5 \mathrm{wt}$. \% $\mathrm{HCl}$. The inhibition may be due to adsorption of $\left[\mathrm{C}_{2} \mathrm{Et}\right]^{+}$on the mild steel surface.

$$
\mathrm{IE}=\frac{\mathrm{CR}_{0}-\mathrm{CR}_{\mathrm{inh}}}{\mathrm{CR}_{0}} \times 100 \%
$$

\section{Electrochemical experiment}

Potentiodynamic polarization curves: Fig. 2a shows the influence of $\mathrm{C}_{2} \mathrm{EtBr}$ on the cathodic and anodic potentiodynamic polarization curves of mild steel in $5 \mathrm{wt}$. $\% \mathrm{HCl}$. It is observed that in the presence of $\left[\mathrm{C}_{2} \mathrm{Et}\right] \mathrm{Br}$, the curves were shifted to more positive or negative potential region and the shift was found dependent on concentration of the inhibitor. The increase in concentration of the inhibitor increase the shift and the decreases. The curves are displaying a preferential suppression of the anodic half reaction.
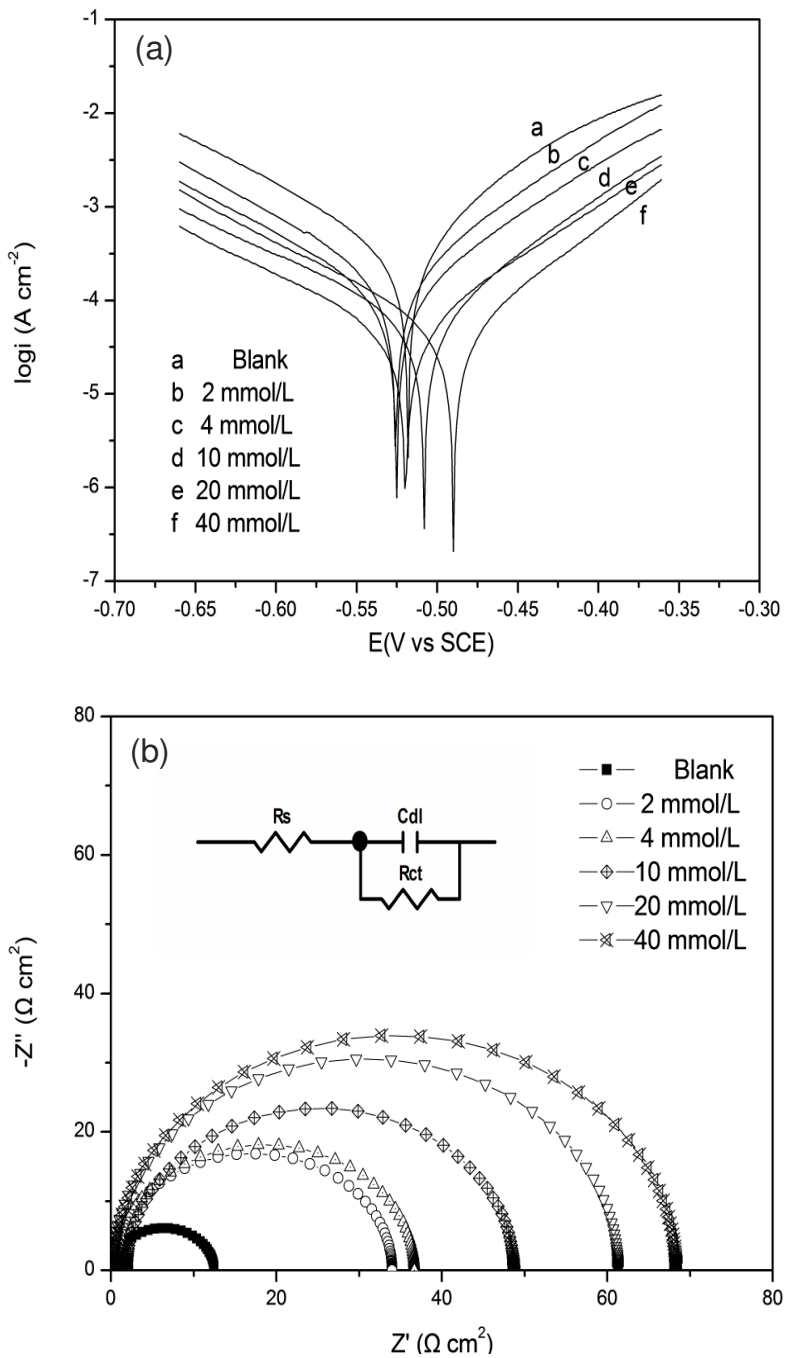

Fig. 2. (a) Potentiodynamic polarization curves for corrosion of MS in 0.5 wt. $\% \mathrm{HCl}$ containing different concentrations of $\left[\mathrm{C}_{2} \mathrm{Et}\right] \mathrm{Br}$; (b) Nyquist plots and the corresponding equivalent circuit for MS in $5 \% \mathrm{HCl}$ in the absence and presence of $\left[\mathrm{C}_{2} \mathrm{Et}\right] \mathrm{Br}$ 
TABLE-2

ELECTROCHEMICAL PARAMETERS FOR CORROSION OF MILD STEEL IN 5 wt. \% $\mathrm{HCl}$ IN THE PRESENCE OF DIFFERENT CONCENTRATIONS $\left[\mathrm{C}_{2} \mathrm{Et}\right] \mathrm{Br}$

\begin{tabular}{|c|c|c|c|c|c|c|c|c|}
\hline \multirow{2}{*}{$\begin{array}{c}\text { Inhibitor } \\
\text { conc. }(\mathrm{mM})\end{array}$} & \multicolumn{6}{|c|}{ Potentiodynamic polarizations parameters } & \multicolumn{2}{|c|}{ Impedance parameters } \\
\hline & $\mathrm{E}_{\mathrm{corr}}(\mathrm{mV} / \mathrm{SCE})$ & $\mathrm{b}_{\mathrm{a}}\left(\mathrm{mVdec}{ }^{-1}\right)$ & $\mathrm{b}_{\mathrm{c}}\left(\mathrm{mVdec}^{-1}\right)$ & $\mathrm{I}_{\text {corr }}\left(\mathrm{mAcm}^{-2}\right)$ & $\mathrm{IE}(\%)$ & $\mathrm{R}_{\mathrm{ct}}\left(\Omega \mathrm{cm}^{2}\right)$ & $\mathrm{C}\left(\mu \mathrm{F} / \mathrm{cm}^{2}\right)$ & $\mathrm{IE}(\%)$ \\
\hline Blank & -518 & 72 & -106 & 0.416 & - & 12.2 & 176 & - \\
\hline 2 & -526 & 80 & -103 & 0.227 & 45.4 & 33.8 & 48 & 64.1 \\
\hline 4 & -525 & 86 & -108 & 0.149 & 64.1 & 36.5 & 35 & 66.3 \\
\hline 10 & -490 & 77 & -104 & 0.619 & 85.2 & 46.8 & 33 & 73.9 \\
\hline 20 & -508 & 82 & -130 & 0.874 & 79.0 & 61.2 & 25 & 80.0 \\
\hline 40 & -520 & 85 & -123 & 0.661 & 84.1 & 67.9 & 23 & 82.0 \\
\hline
\end{tabular}

Electrochemical corrosion parameters such as corrosion potential $\left(\mathrm{E}_{\mathrm{corr}}\right)$, cathodic and anodic Tafel slops $\left(\mathrm{b}_{\mathrm{a}}, \mathrm{b}_{\mathrm{c}}\right)$ and corrosion current density $\left(\mathrm{I}_{\text {corr }}\right)$, obtained by extrapolation of Tafel lines, are collected in Table-2. The values of cathodic tafel slope $\left(b_{c}\right)$ and anodic tafel slope $\left(b_{a}\right)$ of $\left[C_{2} E t\right] B r$ are found to charge with the concentration of the inhibitor, indicates that the inhibitor controlled both anodic and cathodic reactions.

$$
\mathrm{IE}=\frac{\mathrm{I}_{0}-\mathrm{I}_{\text {corr }}}{\mathrm{I}_{0}} \times 100 \%
$$

Equation (2) was used to calculate the IE, where $\mathrm{I}_{0}$ and $I_{\text {corr }}$ are the corrosion current density values without and with inhibitor, respectively. The obtained results show that the inhibition efficiency increases, while the corrosion current density decreases when the concentration of the inhibitor increases. This could be explained on the basis of inhibitor adsorption on the metal surface and the adsorption process enhances with increasing inhibitor concentration. The results obtained from the polarization measurements are in good agreement with those obtained from weight-loss method.

Electrochemical impedance measurements: The corrosion behaviour of mild steel in acidic solution in the presence of $\left[\mathrm{C}_{2} \mathrm{Et}\right] \mathrm{Br}$ was investigated by the EIS. The impedance spectra were analyzed by fitting to the equivalent circuit model shown in Fig. 2b. It is apparent that the impedance spectra obtained yields a semi circular shape. This indicates the corrosion of the mild steel in $5 \mathrm{wt}$. \% $\mathrm{HCl}$ is mainly controlled by a charge transfer process.

Table- 2 collects various parameters such as charge-transfer resistance $\left(R_{c t}\right)$, double layer capacitance $\left(C_{d l}\right)$ and percentage inhibition efficiency (IE) calculated from eqn. (3), where $R_{c t(i n h)}$ and $R_{c t}$ are the charge-transfer resistance values with and without inhibitor, respectively.

$$
\mathrm{IE}=\frac{\mathrm{R}_{\mathrm{ct}(\mathrm{inh})}-\mathrm{R}_{\mathrm{ct}}}{\mathrm{R}_{\mathrm{ct}(\mathrm{inh})}} \times 100
$$

The $R_{c t}$ values were calculated from the difference in impedance at lower and higher frequencies as suggested by Tsuru et al. ${ }^{9}$.

The values of $\mathrm{C}_{\mathrm{dl}}$ are obtained at the frequency $\mathrm{f}_{\max }$, at which the imaginary component of the impedance is maximal $\left(-Z{ }^{\prime \max }\right)$, using the following eqn. $(4)^{10}$.

$$
\mathrm{C}_{\mathrm{dl}}=\frac{1}{2 \pi \mathrm{f}_{\text {max }} \mathrm{R}_{\mathrm{ct}}}
$$

It is found that the $\mathrm{R}_{\mathrm{ct}}$ values increase with increasing $\left[\mathrm{C}_{2} \mathrm{Et}\right] \mathrm{Br}$ concentration while the $\mathrm{C}_{\mathrm{dl}}$ values tend to decrease. The decrease in $\mathrm{C}_{\mathrm{dl}}$ values is due to the adsorption of $\left[\mathrm{C}_{2} \mathrm{Et}\right] \mathrm{Br}$ on the metal surface. The greatest inhibition is observed at a concentration of $40 \mathrm{mmol} / \mathrm{L}$. The inhibition efficiencies, calculated from impedance results, show the same trend as those obtained from polarization and weight loss measurements. In fact, the presence of $\left[\mathrm{C}_{2} \mathrm{Et}\right] \mathrm{Br}$ is accompanied by the increase of the value of $R_{c t}$ in an acidic solution indicating a charge transfer process mainly controlling the corrosion of mild steel.

\section{Conclusion}

From the overall experimental results and discussion the following conclusions can be deduced: (1) The $\left[\mathrm{C}_{2} \mathrm{Et}\right] \mathrm{Br}$ is a new water soluble inhibitor for mild steel in $5 \mathrm{wt}$. \% $\mathrm{HCl}$. The inhibition efficiency increases with an increase of inhibitive concentration to attain a maximum value of $80.4 \%$ at $40 \mathrm{mmol} /$ L. There are good agreements between the inhibition efficiencies, obtained from gravimetric method and electrochemical measurements; (2) The potentiodynamic polarization curves indicated that the inhibitors inhibited both anodic metal dissolution and also cathodic hydrogen evolution reactions and acted as mixed type inhibitors in $5 \mathrm{wt}$ \% $\mathrm{HCl}$ solution; (3) The electrochemical impedance study shows that the application of $\left[\mathrm{C}_{2} \mathrm{Et}\right][\mathrm{Br}]$ inhibitor significantly increases $R_{c t}$ values and decreases $C_{d l}$ values in $5 \mathrm{wt} . \% \mathrm{HCl}$, suggesting that corrosion inhibition takes place by adsorption.

\section{ACKNOWLEDGEMENTS}

This work was financially supported by Hunan Science and Technology (Project No. 2010GK3167) and Hunan Provincial Key Laboratory of Materials Protection for Electric Power and Transportation (Changsha University of Science and Technology) (No.2011CL04).

\section{REFERENCES}

1. H. Ashassi-Sorkhabi and M. Es'haghi, Mater. Chem. Phys., 114, 267 (2009).

2. Q.B. Zhang and Y.X. Hua, Electrochim. Acta, 54, 1881 (2009).

3. Q.B. Zhang and Y.X. Hua, Mater. Chem. Phys., 119, 57 (2010).

4. F.G. Liu, M. Du and J. Zhang, Corros. Sci., 51, 102 (2009).

5. D. Nalini, R. Rajalakshmi and S. Subhashini, Asian J. Chem., 23, 335 (2011).

6. A. Lewandowski and A. Swiderska-Mocek, J. Power Sources, 194, 601 (2009).

7. H.M. Wang, K.L. Huang and Z.P. Zhu, Adv. Mater. Res., 239-242, 1409 (2011).

8. S.M. Zhang, Y.W. Hou and W.G. Huang, Electrochim. Acta, 50, 4097 (2005).

9. T. Tsuru, S. Haruyama and B. Gijutsu, J. Jpn. Soc. Corros. Eng., 27, 573 (1978)

10. L. Elkadi, B. Mernari, M. Traisnel, F. Bentiss and M. Lagrenee, Corros. Sci., 42, 703 (2000). 